\title{
Exploration on the Integration Path of Distance and Open Education and Vocational Education under the Background of "Internet+"
}

\author{
Juan Du \\ Teaching Center, Zhejiang Open University, Hangzhou, China \\ Email: duj@zjtvu.edu.cn
}

How to cite this paper: $\mathrm{Du}, \mathrm{J}$. (2021) Exploration on the Integration Path of Distance and Open Education and Vocational Education under the Background of "Internet+". Open Access Library Journal, 8: e7296.

https://doi.org/10.4236/oalib.1107296

Received: March 9, 2021

Accepted: April 11, 2021

Published: April 14, 2021

Copyright $\odot 2021$ by author(s) and Open Access Library Inc.

This work is licensed under the Creative Commons Attribution International License (CC BY 4.0).

http://creativecommons.org/licenses/by/4.0/

\begin{abstract}
Distance and open education and vocational education are the two main ways of popularization of higher education and cultivation of applied talents in higher education. At present, under the background of "Internet+", distance and open education and vocational education in China are in the stage of mutual integration. The integration of the two types of education is not only conducive to the construction of the "flyover" of lifelong education in China, but also conducive to the construction of resource sharing system, and more conducive to the adjustment, optimization and combination of educational structure and layout, so as to enhance the overall function of education, extend the educational chain and expand the educational space. This paper explores the integration path of distance and open education and vocational education from the aspects of culture, teaching methods, support services and system and mechanism.
\end{abstract}

\section{Subject Areas}

Distance and Open Education and Vocational Education

\section{Keywords}

Distance and Open Education, Vocational Education, Integration Path

\section{Introduction}

The perspective of lifelong learning is the main perspective for people to view distance and open education. Because distance and open education breaks the time and space restrictions, the whole society can become the audience of distance education, and the principle of practical and applied has always been the 
talent training goal of distance education. The occupational characteristics of vocational education are distinct, and the talents training goal of the open and distance education highly, combined with vocational education in the aspect of professional setting and teaching content to have consistent pace with The Times, its each link to open and distance education corresponds to the personnel training demand, make the open and distance education and vocational education development has the possibility of implementation [1].

After entering the Internet era, the ubiquitous "Internet+" background makes the concept of lifelong learning become a consensus in the era of knowledge economy, and people have more open demands for vocational education, making vocational education become a universal public resource that can be accepted by every citizen. Although vocational education has great advantage in the cultivation of technical talents, but their on-the-job education and post-career education stage before its popularity is still not enough, and the characteristics of open and distance education based on Internet is conducive to help teaching vocational education breakthrough space constraints, widen the category of vocational education, the vocational education to keep up pace to adapt to the social demands for category and job responsibilities of upgrading [1].

\subsection{Explaining the Concept of Distance and Open Education and Vocational Education}

\subsubsection{Distance and Open Education}

As a form or type of education, the teaching idea of open education originated from the French educator Paul Langerang in the 1950s. it is a wide range of philosophical concepts, is an ideal of human education pursuit of perfection, its core is the openness, both in the study object, learning resources, and in many aspects, such as learning environment, with learners as the center, break through the restrictions of traditional education, make education development into a new realm, eventually achieve "to learn all the time, everyone study, always can learn" the ideal situation, realize the goal of lifelong learning.

Distance education, or distance education, as a form of education, is opposite to classroom face to face education, is a discontinuous face to teach education. Desmond Kegon, a foreign scholar. According to Desmond Kegon distance education has the following characteristics: teachers and students are separated for a long time, educational organizations play an important role in teaching preparation and student support service preparation, and technical media connect teachers and students as the carrier of course content [1] [2].

The nature and characteristic of open education decide it naturally and distance education is inseparable, therefore people habitually call open education and distance education together distance open education. The organizations engaged in distance and open education mainly include the national Open University system and the departments engaged in distance education or continuing education in ordinary colleges and universities. 


\subsubsection{Vocational Education}

As a concept corresponding to academic education, vocational education mainly refers to the activities of pre-service education and post-service education for the purpose of enabling the education objects to acquire certain professional knowledge, attitude and skills, and to form good professional ethics and discipline, so as to meet the needs of a certain post.

Higher vocational education is an important part of education in our country, including college education, higher vocational education and adult higher education, is a type of education development, shouldering the mission of training talents for economic and social construction and development, at the same time, the higher vocational education and higher education in the vocational education system of China [2].

\subsubsection{The Integration Path}

Integration here refers to the distance and open education and vocational education exchanges and communication, learning from each other, to achieve joint development, to achieve a win-win goal. The pertinence and flexibility of vocational education and the openness and universality of distance education provide a foundation for the communication and fit of the two kinds of education. It is the distance vocational education proposed by many scholars to combine distance education with vocational education in depth as a method, means and strategy to better promote the development of vocational education [3]. In this way, the best idea, the best teachers, the most advanced technology and other remote means can be spread to all directions, promote the opening of vocational education, and realize the theoretical symbiosis, practice integration, social service, individual development and other goals of vocational education and distance education. The integration path is for this goal, the research method and process in the integration process of distance and open education and vocational education [4].

\subsection{The Background of the Integration of Distance and Open Education and Vocational Education in China}

Based on the country in the new era of education reform and development plan outline, should actively build flexible open a lifelong education system, especially should pay attention to do a good job in modern education, combined with the continuous development and change of information technology, should optimize the examination system of higher education reform, the continuous development of modern distance education, for students and learners to create a more flexible and personalized learning conditions, open distance education is carried out based on Internet technologies, with the help of open and distance education system can effectively break the traditional in the sense of time and space constraints, and new education effective way to build up a learning society. State and the government have always attached great importance to vocational education in the new period, also proposed should continuously optimize and improve the 
vocational education talents diversified channels, and the growth of culture theory education should not only pay attention to the learners, but also to vocational skills education, so that students can accept to the more diverse the higher vocational education effectively [3].

At present, with the sound development of China's overall vocational education, the various education system is also gradually improved, to cultivate more diversified comprehensive high-quality hot talents for the society and the industry. Not only effectively improve the comprehensive quality of professionals, but also for the social and economic development and steady development of the industry to lay a good foundation. Vocational education in the new period and there are still some differences between degree education, so in the process of the construction of vocational education, should be combined with vocational education and establish a flexible communication between diverse learning system integration mechanism, thus effectively realize learning society construction goal, also can effectively improve the quality of talent study, better improve the overall level of professional learning of open and distance education [4].

After entering the 21 st century, the distance education based on the Internet is faced with new breakthrough requirements. At the National Education Conference, the central government made it clear that distance and open education should be integrated into other forms of education. From the perspective of current economic development and education background, the pure education of distance and open education and vocational education has been unable to meet the requirements of the "Internet+" era. To solve this problem, the integration of distance and open education and vocational education is the inevitable trend of the development of The Times. Restricted by history and realistic obstacles, the integration development of the two types of education also needs to establish practical short-term goals and long-term development plans, to solve the preliminary integration level, and to realize the three-dimensional construction of the integration of the two types of education from the gradual changes of the environment. Distance and open education and vocational education have both similarities and differences. We should actively seize the opportunity and take effective measures to promote the integration of the two types of education under the background of "Internet+" [1] [2].

\section{The Main Form of Communication between Distance and Open Education and Vocational Education}

The distance vocational education in developed countries started earlier, and they have accumulated rich experience in distance open education and vocational education. The main forms of running schools are as follows: 1) vocational education in comprehensive universities or open universities, represented by Boston University in the United States and Open University in the United Kingdom. 2) Vocational colleges carry out a variety of vocational Education, such as American community colleges implementing "distance Education + 
face-to-face teaching” And credit system, German Landau Vocational Training Institute integrating distance Education And vocational Education with "distance Education + on-campus practical training”, Australian TAFE Institute (Technical And Further Education) And Canadian Holland College. 3) Distance education institutions carry out vocational and technical education, such as Open Learning Australia (OLA) in Australia and Open Learning Agency in Canada, which achieve the docking of distance education and vocational education [5].

At present, there are mainly three forms of communication using distance and open education and vocational education in China:

The first is the dual track mode of distance and open education and vocational education, which is formed by the Open University of China. For example: 1) The "One Student in a Village Plan", which is entrusted by the Ministry of Education and implemented by TVU, explores modern distance education methods to carry out higher vocational education in rural areas, which has made important contributions to improving farmers' quality and developing local economy. 2) The mode of running vocational schools carried out by local TV universities, using high-quality educational resources to carry out vocational education and set up vocational and technical colleges. For example, we are familiar with Hangzhou TV University and Hangzhou Vocational College of Science and Technology, Wuhan TV University and Wuhan Software Engineering Vocational College [5].

The second is that higher vocational colleges and colleges of distance education jointly run distance open education. Since 1998, the Ministry of Education officially approved four universities such as Tsinghua University and Zhejiang University to carry out modern distance education pilot, distance open education and vocational education between more and more tend to integration. The open distance education jointly run by higher vocational colleges and key universities not only makes up for the shortage of teaching resources and teachers in higher vocational colleges, but also expands the conditions and levels of running schools in traditional colleges and universities.

The third is that vocational colleges use distance education platform to try to communicate with distance education and vocational education, as well as the distance vocational adult education platform led by vocational colleges, industries and large enterprises or Open University and TV University [4].

\section{The Main Ideas and Methods of the Integration of Distance and Open Education and Vocational Education}

In March 2015, Premier Li Keqiang proposed the "Internet+" plan for the first time at the Third Session of the 12th National People's Congress. The idea of "Internet+" has spread rapidly in China's economic field. In May 2015, prime minister Li in the "vocational education cycle" and made clear that to promote to speed up the development of modern vocational education, broaden the life- 
long learning channels, reiterated the eighteenth big proposed, open and distance education, vocational education in common colleges and universities to strengthen interaction, to establish smooth communication between different learning system of the overpass. With the advent of "Internet+" and the boom of lifelong learning, we are faced with the comprehensive reform in the field of education. In this context, the distance and open education of RTVU, which is based on the Internet, and the vocational education which is closely related to the lifelong education in China, have opened the prelude to the interactive integration. Although distance and open education and vocational education have clear independent attributes, they also have a lot of complementary space. Under the background of "Internet+", the research on the integration path of distance and open education and vocational education is an important and necessary subject at present [6].

The complementary characteristics of distance and open education and vocational education enhance the possibility of the integration of distance and open education and vocational education. Under the current background of "Internet+", the integration of distance and open education and vocational education in China can be started from the following aspects.

\subsection{Build a New Way of Learning}

Under the background of "Internet+", people's learning styles have changed a lot. For the integration of distance and open education and vocational education, the construction of new learning styles is also an important content and basic path of the integration. To some extent, the success of the integration of the two types of education depends on the way students learn. The change of learning style is one of the breakthrough points for the integration of distance and open education and vocational education.

In the era of "Internet+", learners' learning styles have changed a lot compared with traditional classrooms, courses and teaching modes. With the increasing popularity of modern digital learning fields and intelligent learning environments under the background of "Internet+" such as MOOC and digital library, learners' learning becomes more personalized. However, the distance and open education still has shortcomings in the in-depth interaction of face-to-face classroom, and the vocational education still has shortcomings in the online learning. To realize the integration of the two, it is necessary to build a new learning method adapted to the "Internet+" background [6].

\subsection{Reconstruction of Open Management System and Teaching Staff}

At the beginning of operation, distance and open education and vocational education operate according to two management systems. Naturally, there are many system and mechanism models, and the separation of institutions and personnel brings difficulties to the integration of the two kinds of education. Therefore, in 
order to realize the integration of distance and open education and vocational education, we should actively restructure the open management system and teachers under the background of "Internet+". For the integration of distance and open education and vocational education, the main practical task should be undertaken by teachers. If the open management system is the basic carrier of the integration of the two types of education, then the construction of teachers is the starting point of the integration of the two types of education.

\subsection{Establish a Sound Mode of Resource Sharing and Joint Construction}

The same talent training system is the basic condition for the integration of the two kinds of education, and it is no exception in the integration of distance and open education and vocational education. In order to build the same talent training system for distance and open education and vocational education, it is necessary to establish a perfect mode of resource sharing and co-construction, through which the resources of the two types of education can be matched and integrated, and the generation of integration representation of distance and open education and vocational education can be promoted [5].

In addition, under the background of "Internet+", the open and distance education and vocational education also can strengthen the digital resources sharing, through vigorously promotes the resources construction, improve the quality of online learning resources, in turn, promote to promote the efficiency of resource use, make two kinds of education can realize the purpose of improving the quality of talent training, especially by sharing digital resources, strengthen the teachers' understanding of the two kinds of education, promote the rapid integration of the two kinds of education [6].

\section{The Representation of the Integration of Distance and Open Education and Vocational Education}

For the Open University, the integration of the two types of education can realize resource sharing and mutual learning, and output strong endogenous driving force for the long-term development of the university. The two kinetic forces work together and support each other. The integration of distance and open education and vocational education is embodied in the following four characteristics:

\subsection{Cultural Integration}

In order to realize the integration of the two kinds of education, we must find the common mission, which is the first task of cultural integration: the formation of the common mission. "Mission is people's recognition of the social responsibilities that an organization or an individual must undertake". Only under

the premise of a common mission can we jointly carry out "purposeful and planned activities to cultivate people". Distance education and vocational educa- 
tion have similar missions, that is, to improve the professional quality of social people, to adapt to the needs of economic and social transformation and development [7].

Through the interaction with the learning environment, people acquire cultural nourishment and complete their own construction. Therefore, it is necessary to combine the unique network learning culture of distance education with the unique culture of pursuing professional ability of vocational education. The common feature of both is the true-seeking and pragmatic training of applied talents. Therefore, cultural integration needs to create a realistic and pragmatic material environment, through the shaping of the environment, to form a cultural field to cultivate applied talents.

\subsection{Integration of Teaching Methods}

Whether it is distance education or vocational education, no matter the characteristics of the learners' times, the needs of The Times, the process of adaptation and the factors related to adaptation, no matter how good the teaching method is, it is useless. For remote education, represented by the Open University, radio and TV university distance education the main body of online education experience, idea, research is walking in the forefront, but in the Open University, radio and television university teaching has not abandoned the traditional face-to-face, traditional face-to-face as Open University, radio and television university to primary school appraisal key elements are still at work, show that the Open University, radio and television university teaching need face-to-face teaching in order to make up for the inadequacy of online education. On the contrary, vocational education has encountered the problems of too short learning time, too much learning content and too old learning methods, and it is urgent for online learning to make up for them. This is also the reason why MOOC and other online learning methods have attracted high attention from the senior management of vocational education. The author believes that certain face-toface teaching and certain online learning can form a complementary cooperative teaching mode. First of all, online teaching represented by MOOCs has gradually become the main means of knowledge construction through high-quality resources, good experience, full interaction and free from the constraints of time and space, which represents the requirements of the construction of lifelong learning society for the cultivation of learning methods. Secondly, face-to-face teaching, through consolidating the belief in course learning, direct interaction between teachers and students and face-to-face guidance in practice, has more advantages in improving vocational ability and has become an indispensable link in education [7].

\subsection{Support Service Convergence}

The support service covers the direct support service of learning, including teaching materials, teachers, classrooms, laboratories and other services. Learn- 
ing support services, including learning and research methods, reference materials and other services; Indirect learning support services, including student loans, psychological counseling, learning equipment rental and technical support services. In addition, learning skills as well as learning psychological and emotional needs are also involved in learning support services. The transformation of teaching methods has resulted in a unified development direction of supporting services, including online learning resources, learning skills and learning psychology, as well as face-to-face learning materials, teachers, laboratories and so on. With the maturity of thinking mode of big data technology, individualization, timeliness, precision and intelligence have become the development direction of modern support services [6].

\subsection{Integration of Institutions and Mechanisms}

The educational system refers to the general term of the rules and regulations that educational implementing institutions and educational management institutions guarantee the normal operation of educational institutions through the establishment of various educational norms at all levels. Mechanism is about the interrelation of educational phenomena of each subsystem in education and its operation mode. In school education, the educational system is the foundation of organization, and the educational mechanism is the guarantee to restrict the occurrence of non-standard behaviors and guarantee the normal teaching process. In the process of the integration of the two types of education, we should seek external drive from the system and rules, and establish an in-depth communication mechanism suitable for the two types of education. Only through in-depth communication can we effectively understand, and only through effective understanding can we form a common mission and ensure that the school-running behaviors supported by the common mission develop in an accurate direction [7].

\section{The Realization Path of the Integration of Distance and Open Education and Vocational Education}

Distance and open education should exist as an educational concept from the perspective of lifelong learning, and provide learning opportunities and resources for all the public who have learning needs in the society. It provides short-term learning opportunities for scholars who have completed campus education, and is an important supplement to campus education. Distance and open education as a teaching mode, "with the help of modern distance and open education means, organic combination of face-to-face teaching, correspondence and self-study forms, effective allocation of a variety of media education methods". This way of education enables teachers and students to go beyond the limitations of time and space, conduct interactive learning, break the spatial limitations of education, and make the audience of distance and open education become the public of the whole society. The training goal of distance and open 
education has always adhered to the principle of practicality and application, and cultivated the talents who are "able to go, stay and be used". Vocational education, because of its professional characteristics, insists on training a large number of high-quality, high-skill professional talents. The two have the greatest degree of coincidence in the culture objectives. The professional setting and teaching content of vocational education should keep up with the needs of The Times and the changes of economic development, and the talents cultivated should meet the needs of the labor market, adapt to the needs of the post, and promote the development of economy and society. From the micro level, the course setting, teaching content, teaching evaluation and other links of vocational education all reflect the training of employment-oriented, professional quality and vocational skills, which fits the talent training objectives of distance and open education and makes it possible to integrate the two development [1] [2].

Therefore, teachers and administrators should strengthen the standardized management of open education. Enhance standardized management and service consciousness, further improve the teaching organization, course management, course evaluation and teaching support services of various measures. Improve the online teaching evaluation and incentive mechanism, optimize the online course teaching design. Strengthen the construction of a relatively stable teaching team that combines full-time and part-time jobs, and organize and carry out novel and effective online teaching activities featuring interaction between teachers and students in various forms. We will strengthen the development, co-construction and introduction of curriculum resources. Continue to comb, integrate, update and optimize teaching resources to improve pertinence and effectiveness. We will actively promote the reform of open education examinations, expand the pilot scope of open and semi-open examinations of provinsial-administered courses, improve the teaching links of "formative assessment", strengthen the construction of examination style and discipline, and enhance social reputation and public trust [4].

The talent training goal of vocational education is to cultivate technical talents with "high, fine and special", that is, skilled and professional talents with high level of professional quality, who have a more profound study of a professional field and mastered a professional technology. The cultivated talents should not only have high humanistic quality, but also have solid scientific basic theoretical knowledge, but also be proficient in professional skills [2]. When the educatees in the system of vocational education go out of school and become professionals, the development of their career is a continuous and dynamic process, which is faced with the development of vocational field, the renewal of post skills and the constant change of professional quality requirements. At the same time, with the continuous adjustment and renewal of industrial structure, emerging industries will sprout, and outdated technologies and posts will disappear accordingly [6]. In the process of career development, one needs to constantly adjust one's pro- 
fessional quality and ability to adapt to the updating of post categories and responsibilities. As a result, pre-entry education, vocational qualification training, post transfer education, vocational skills training and other vocational education are indispensable. It can be seen that the process of vocational education should not only stay in the scope of campus education, but also cover the two stages of pre-service education and post-service education.

Therefore, the Open University should earnestly do a good job in teaching platform, resources, management and learning service support, do a good job in the basic work for promoting the operation of the Open University, and strive to build a service system of nationwide learning, lifelong education and the construction of a learning society. Actively explore academic education and nonacademic education, distance education and vocational education, pre-service education and post-career education effective connection way, gradually perfect the system of open, flexible mechanism, communication channel, choose a variety of open education management system and operational mechanism, the research for single recognition, mutual recognition of different kinds of learning outcomes, and gradually form credits accumulation of storage, achievements, conversion, certification mechanisms [7].

By combing the theory and practice of the integrated development of distance and open education and vocational education, and combining the viewpoints of experts and scholars, the author believes that the realization path of the integration of the two types of education can be implemented from the following four aspects:

\subsection{Identify the Common Mission of the Two Types of Education}

As far as the integration of distance and open education and vocational education is concerned, the development of modern education urgently needs the integration of online learning and classroom learning, not only to meet the requirements of education modernization, but also to form the driving force of lifelong learning society in the competition with the core competitiveness of advanced countries. The essence of both types of education is vocational education. For example, the Open Education College of Zhejiang Open University and the Vocational College aim at cultivating talents, both of which serve to improve the professional quality of the people. Two kinds of education the ultimate ownership is under the system of lifelong learning education organizational form, we need from the "global" and "future" in the perspective of two kinds of education promote the mission of vocational ability, into two kinds of education needs to provide society with the aim of teaching, scientific research and social service, ideal, purpose and responsibility [8]. Only when we have established our own development mission, can we determine the goals and operation mode of the organization according to the mission. The common mission of vocational education and open and distance education is to cultivate professional ability, improve the professional quality of the population in the whole society, it is the 
mission of the integration education development foundation, needs to be on the basis of some combination of national modernization and education and technology demand of find the proper balance depth integration, formed two kinds of education can mutual understanding, respect and practice mission, to self, self adjustment and self-improvement.

\subsection{The Establishment of Two Types of Educational Integration Mechanism System}

The integration and development of the two kinds of education need to establish a perfect mechanism and system, and it is the guarantee to realize the integration, used to coordinate and maintain the relations of various responsibilities and rights, and form the standards of work and behavior for the integration and development. First of all, the school should make clear the relationship between its own development, the external market and the society, and find a balance between the two, so as to take this as the basis of system construction [4]. That is to say, in order to meet the social requirements for the development of schools, institutional construction should also form a system that is not subject to too many external constraints on its self-development and provide a relatively stable institutional framework. Secondly, to build the institutional foundation of the integration of the two types of education. Such as the Open University, zhejiang institute of education and vocational college professional "preschool education", can make the same quality standards, the same talent training scheme, etc., and implement all kinds of learners course selection, curriculum standards, the talent training scheme is consistent, the formation of two kinds of education "overpass" and other ways to communicate, make the development of the two kinds of education unified in the same faculty, curriculum, technology and support services to shape the learning environment [1]. Thirdly, at the teacher level, appropriate standards should be adopted to promote the institutional construction of the integrated development of the identity of the two types of education. Zhejiang Open University teaching faculty is in the center of the two kinds of education financing and Shared each other, such as the open and distance education to online support services should also be based on appropriate standards certification class, with a unified evaluation mechanism, the title promotion mechanism, rewards and punishment mechanism to treat school teachers, teachers of integration development of identity. Of course, the construction of the mechanism and system cannot be accomplished overnight. It needs to form a constantly revised mechanism under the call of mission and various management problems exposed in the actual operation, so that the construction of the mechanism and system can be improved like a normal life body [8].

\subsection{Information Technology Is Deeply Integrated with Education and Teaching}

The integration of information technology and education and teaching is the foundation of the integration of the two kinds of education. From the perspec- 
tive of the development of distance and open education and vocational education, there are essentially the same development needs, that is, the deep integration of information technology and education and teaching. Over the years of distance and open education, I have accumulated a lot of experience in the field of online education, and my educational technology ability has been greatly improved, and my ability to perceive the change of educational technology has been strengthened. However, it is easy to find many shortcomings in the distance and open education from the perspective of the integration of educational technology and teaching. Similarly, in the face of the impact of online learning paradigms such as MOOC and the reflection on the lifelong learning ability of the talents it cultivates, vocational education aimed at shaping and developing future vocational technology also needs to cultivate information literacy and lifelong learning ability in an environment integrated with information technology and education and teaching [5]. Also, under the background of integration development, open distance education online learning experience and technology through the synergy mechanism is applied to the integration development needs, to promote vocational education personnel training quality, vocational education in the use of advanced information technology through the interaction of people get timely, can promote the technology applied in online learning more smoothly. Such as Zhejiang Open University repository, lifelong learning and vocational training center can share with each other and integration, the integration of the final performance, does not distinguish between online learning and online learning development direction for the future of the school, the need to create a deep learning environment, the depth of the formation to help students find and solve problems learning efficiency, the use of information technology at the same time provide more attractive for learners personalized learning content and resources and eventually form without distinction of "professionals" culture. Of course, the integration of information technology and education and teaching needs the integration of programs supported by various technologies and the transformation of teaching paradigms, as well as continuous progress of technology itself [8].

\subsection{Implement the Teaching Behavior of the Integration of Two Kinds of Education}

Implementing the teaching behavior of the integration of the two kinds of education is the way to achieve the goal of integration. In order to realize the integration education teaching behavior, first of all, to change the teachers' ideas, to the concept of "learner center" in the first part of the daily education teaching, from the learner's "modernity" to consider the value of online learning, from the consideration on the learners "complex task oriented complete tasks to the learner's forging, from the learner's" personalized “consider targeted learning strategy, the implementation to the education teaching, need teachers from the traditional" teacher center "truly free, voluntary integration construction. Second, we should guide learners to change their learning styles to adapt to the 
integration of the two types of education. Vocational education needs to focus on talent cultivation by introducing advanced online resources such as MOOC, and more importantly, it needs to promote learners to adapt to the change of learning mode oriented to the needs of lifelong learning through online learning resources such as MOOC. Distance and open education should further optimize the online training experience, integrate vocational education resources into the training base, and further improve the ability of distance and open education talents to face real tasks [1]. Through such transformation, the convergence of learning methods of the two types of education will be gradually realized. Thirdly, quality control of the two types of education should be carried out through formative evaluation and summative evaluation of the same standard, so as to achieve the consistency of "quasi out" standard. Distance and open education is questioned in the era of TV University because of its relatively loose graduation standard, which results in a series of weakening of management effectiveness. Vocational education is facing some quality problem, is due to their own quality standards set in the direction of too much emphasis on knowledge itself, and ignore the formation of professional skill evaluation, the same standard to make vocational education and open and distance education to communicate with the outside world, in the construction of brand, cultivating brand and brand influence on a greater role [7].

\section{Summary and Prospect}

After the strategy of the integration of the two types of education is determined, how to realize the integration is a problem that researchers must think deeply. The integration of the two types of education should take teaching mode as the breakthrough point, strive for policy support, establish the system and mechanism of the integration of the two types of education, cultivate the teachers who can adapt to the integration of the two types of education, and form the integration of the two types of education with resource co-construction as the basic way and cultural construction as the auxiliary.

To achieve smooth integration of the two kinds of education, the integration education development is the future need to be clarified the mission of school development, set up the system of the integration education mechanism to ensure the smooth implementation of integration of information technology and education is to achieve the integration education teaching depth integration, the basis of implementing the integration education is to realize the integration of teaching behavior target of the implementation of the approach [2].

After looking to the future, the integration of open and distance education and vocational education is the modern open vocational education, the system will adapt to the growing demand for education and learning, in promoting the lifelong education and learning society to find the orientation of their own, continue to adhere to the reputation and the quality is the life, the high quality service is the foundation, strengthen the open and system construction is the fu- 
ture, efficient operation is the guarantee of educational philosophy, is committed to gather the high quality learning resources, provide considerate support services, run efficient scientific research network, to carry out the living building open modern vocational education system with Chinese characteristics, A platform for service national lifelong learning platform, to build a learning society and a harmonious socialist society to make a greater contribution to let the future of modern distance vocational education more deeply reflect "everyone to learn, always can learn all to learn", education fairness, service construction of lifelong education system and learning society. We will strive to build modern distance vocational education into an important pillar for the construction of lifelong education system and learning society, and build a wide and limitless knowledge space that transcends time and space for the whole people to learn and learn for life [3].

\section{Found Project}

This paper is the research result of Zhejiang Radio and TV University 2019 Annual Scientific Research Project (Youth Project), Project No.: XKT-QN006. It is also the result of "Development and Implementation of Project-based Learning Curriculum Based on Core Literacy Cultivation", Higher Education Teaching Reform Project of Zhejiang Radio and TV University in 2020, Project No.: XJG202001.

\section{Conflicts of Interest}

The author declares no conflicts of interest regarding the publication of this paper.

\section{References}

[1] Liu, Z.F. and Ding, W.J. (2018) Research on Strategic Goal, Basic Guarantee and Realization Approach of Open University Development in China. China Video Education, No. 7, 54, 55.

[2] Wu, N.Z. (2016) Representation, Time Series and Implementation Path of the Integration of Distance and Open Education and Vocational Education. Research on Continuing Education, No. 6, 45.

[3] Liu, W.X. (2017) Problems and Paths of the Integration of Distance Education and Vocational Education: Education and Occupation. No. 9, 111.

[4] Song, P. and Shen, X.F. (2018) The Present Situation, Dilemma and Management Way of the Integration of Distance Education and Vocational Education from the Symbiosis Perspective. Adult Education, No. 1, 19.

[5] Hallinger, P. and He, L.J. (2013) Leadership for Learning: Models and Key Dimensions. Journal of Education Research, No. 12, 121.

[6] Guo, Q.X. (2013) Rational Thinking on the Curriculum Status of Vocational Education-Based on the Perspective of Macro Policy. Education Research, No. 10, 83.

[7] Peng, F.X. and Yang, Y.L. (2013) Building a High-level Open University with Vocational Characteristics. Hunan Radio and TV University, No. 4, 10-13.

[8] The State Council (2010) National Medium- and Long-Term Plan for Educational Reform and Development (2010-2020). 